\title{
Socio-Commercial Agri-Biotech Model for Rural Development in India by Combining Livestock and Organic Farming Practices
}

\author{
Abhishek Cukkemane* \\ Bijasu Agri Research Laboratory LLP, Kondhwa, Pune-411048, Maharashtra, India
}

Received: 21 November, 2016; Accepted: 05 December, 2016; Published: 08 December, 2016

*Corresponding author: Abhishek Cukkemane, Bijasu Agri Research Laboratory LLP, Kondhwa, Pune-411048, Maharashtra, India, Tel: +91-8888-230077,E-mail: director@bijasu.org

\begin{abstract}
India experienced major success in agriculture productivity, post-green revolution, due to use of fertilizers. Around the same time, operation flood made India from a milk-deficient to highest producer by introducing exotic breeds. These approaches resulted in food and milk security but at a cost of decrease in soil health and loss in animal farming especially indigenous breeds of cattle. Since few years, educated medium land holding farmers have adopted organic farming practises. But, the supply of high quality organic manures remains a bottle neck in many sectors. It is therefore necessary to highlight the importance of combining organic- and cattle farming to the rural folk by introducing socio-commercial models based on modern biotechnological processes that can convert animal wastes into high quality manures on a mass-scale that can be efficiently marketed in the rural areas. Such practise will make small and medium land holding farmers adopt cattle farms, which will in turn be an epicenter for rural development by constant supply of manures to the farmers at a reasonable price. Therefore, we briefly highlight the impact of farming revolutions and the problems faced by farmers in India. Our analysis of the total cattle waste in India and the area of arable land, we highlight the possibility of organic farming across the nation. By utilizing readily available raw materialist is possible to accommodate socio-commercial model that can result in revenue generation by combining organic- and animal- farming practises for agronomic and rural development.
\end{abstract}

Keywords : Socio-corporate; Agronomic; Organic farming; Cattle rearing; Rural development; Environmental friendly

\section{Introduction}

Soil is one of the most important hosts which influence various biogeochemical and microbial processes. Traditionally, maintenance of soil health in Indian farming was based on animal wastes from farm especially cattle to replenish organic content. Reformation of Indian agriculture under green revolution in the late 1960s [1] and white revolution that began in 1970 [2,3] has raised food and dairy production, which aided millions in India and made it self-sufficient and food secure. But usage of chemical fertilizers and pesticides has led to decrease in organic content of soil taking a heavy toll on the environment and other useful flora-fauna [4]. This resulted in poor soil health, less crop yield and overall economic loss to farmers. Therefore, it is pertinent to develop faster and efficient Organic Manures (OM) by improving traditional approaches of organic farming by incorporating latest biotechnological that can compete and curtail the use of their synthetic counterparts.

For example, organic fertilizer like Kunapanjala [5], has been successfully used in the state of Sikkim, India, which was officially declared an "organic state" previous year. Yet in many other parts of India, unprocessed animal waste such as cow dung is directly applied to the field which maintains soil health but does not provide yield comparable to synthetic fertilizers. Therefore it is important to produce $\mathrm{OM}$, for modern farmers that have a short processing time, efficient and high yield providing qualities such as Panchagavya and Jeevamrut [6-8] that has met with decent success in West and South Indian states, which are prepared by fermenting cow dung and urine. Recently, we performed metabolomic analysis and have identified the various biochemical's that make these OM efficient for agriculture purposes [6]. Although very efficient, these $\mathrm{OM}$ are used by a small percentage of the farming communities' i.e. 650,000 hectares [9] in a total arable land of 160 million hectares [10]. This is because of several short- comings such as: preparation time (1030 days); manual mixing (laborious and expensive); undesirable results and off-odors (if not mixed properly) causing farmers to abandon organic farming practises and reverting to synthetic fertilizers that are readily available and easy -to-use.

Hence, the need of the hour is to develop technology and strategy for preparation of $\mathrm{OM}$ which will overcome all the above mentioned short-coming sand increase farmer's revenue. To incorporate all these benefits it is necessary to develop model wherein, cattle farms have an electrically driven fermenter, installed to produces the above mentioned OM in 7-10 days. Such an agronomic model should incorporate various social and cultural values for successful rural development. In this review, we consider various factors in rural India and the prospect of socio-commercial system that can benefit the rural farming society at large. 


\section{Cattle Farming and Biodiversity- More the Merrier}

Cattle rearing hold a very significant religious and cultural value in Indian farming society. It is revered as an esteemed practise but two major agricultural revolutions have negatively impacted it.

Impact of green revolution: Before the green revolution and introduction of chemical fertilizers, animal farming was an important mainstay of agricultural activities, which maintained the organic content of soil. This is chiefly expressed as the C:N ratio, such as soil condition, the nature of applied organic manure and the crops that were cultivated. Farmers resorted to adding animal dung and mixed/inter cropping to maintain a steady balance of C:N ratio of 20:1 as suggested by the Indian council of agricultural research [11]. But now, with the extensive use and ease in the availability of synthetic fertilizers, farmers abandoned their sizeable live stocks, which indirectly resulted in gradual decline of organic content of soil over many decades.

Impact of operation flood: Operation flood helped to improve the scenario of dairy farming in India but caused gradual decrease in the rearing of indigenous cattle. Interestingly, the Indian breeds are resistant to drought; consume less water and feed, which result in lower yield of milk. Typically, an average Indian cow provides milk ranging from 5 to $15 \mathrm{~L} /$ day, though some well-maintained breeds can provide up to $20 \mathrm{~L}$. But, dwarfs in comparison with the exotic varieties like Jersey and HolsteinFriesian, which produces $20 \mathrm{~L} /$ day on average. To increase milk capacity, the administration encouraged farmers to rear the exotic species of cows which caused major loss in the biodiversity and population of indigenous cattle breeds [3]. As of now, it is estimated that India has 190 million cows out of which only 33 million account for the 37 indigenous breeds [12,13]. In the last 16 years, India has experienced 4 periods of drought. These episodes caused farmers to rear indigenous breeds of cows because of their drought tolerance quality and moreover the success story of Brazilian farms rearing high milk-yielding Indian cattle varieties encouraged them to follow their footsteps.

\section{Is It Possible to Cultivate The Entire Nation Solely by Organic Farming?}

India has a total of 328.7 million hectares of land and is the second largest country after the United States of America in total arable land. Estimates suggest that 160 million is arable, but only 95 million is utilized [10]. It highlights a major agricultural concern of under-utilization of nearly $33.33 \%$ of the arable land. This raises a very important question, i.e., is it possible to apply the organic farming technology to the entire arable land in India?

Let us perform a simple calculation considering that a cattle produces $10 \mathrm{Kg}$ of cow dung, therefore 37 million cattle will produce 370 million Kg of dung daily. Assuming soil of $1 \%$ organic carbon (OC), this is usually enriched in the top soil $0-10 \mathrm{~cm}(0-0.1$ $\mathrm{m}$; also called humus layer) with a bulk density of $1.4 \mathrm{~g} / \mathrm{cm}^{3}$. One will require adding $10,000 \times 0.1 \times 1.4=1.44$ tonnes $\mathrm{Kg}$ of organic carbon per hectare $\left(10,000 \mathrm{~m}^{2}\right)$. Generally, cattle waste contains $\sim 15 \%$ OC [14]. Therefore, one needs to add $93.24 \mathrm{Kg}$ of cow dung to get a soil of $1 \%$ OC content; for 160 million hectares, a total 14,918 million ( 15 billion) $\mathrm{Kg}$ of dung will be required. By only using cow dung from indigenous varieties, soil application is possible every 40 days assuming $100 \%$ utility of the organic matter. But if we were consider the entire cattle population of 190 million then the application rate would be weekly. Cow cattle are the third largest milch animal across India, which would imply that the total animal waste generated should suffice for regular application on all arable plots.

\section{But what are The Problems Faced by the Farmers in Using Agricultural Wastes?}

Animal dung represents complex undigested material that is broken down into simple biochemical and metabolites gradually over a period of 3-6 months, whereas chemical fertilizers are ready to use. Furthermore, it may contain harmful pathogens that may prove to be life threatening $[15,16]$.

Apart from this, several policy making bodies have advocated usage of chemicals for over 5 decades due to which the current generation of farmers have lost traditional farming knowledge and practise are not willing to take up organic farming because it is labor intensive and cumbersome. Lastly, poor education and awareness of farmers have played a major share. For instance, China adopted and practised biogas technology [17], whereas the rest of the world moved towards green revolution. With this, China not only benefited from harvested of gas-energy but also used OC rich slurry, which is processed manure devoid of pathogens, for farming purposes along with judicial use of chemical fertilizers.

\section{Socio-Economic Model}

The socio-economic situation amongst Indian farmers is rather heterogeneous. More than $60 \%$ are small land holders (1-3 acres of land), 19\% fall into the medium land holders (4-9 acres) and $7 \%$ are large farmers ( $<10$ acres). Landholding size and governmental initiatives are important factor determining motivation and agriculture as a good $[18,19]$ source of income. In many cases, middle and large scale farmers have other sources of revenue $[19,20]$ apart from farming. The larger farmers prefer any farming technology and inputs that increase their crop yield, but it is the middle scale educated farmers and to some extent small scale farmers who practise organic farming. Small land holding farmers on the other hand are heavily dependent $[19,20]$ on the outcome of their yield and hence are not willing to take up organic farming practises. Therefore, it is important to develop socio-commercial models that will encourage them to adopt organic farming practises, reduce their spending and improve their livelihood.

A very important criterion in rural development is selfsustenance, which is reflected by the agricultural output and index above poverty line. The cost of chemical farming is directly related to petroleum costs, which has increased considerably since 1960s. Recently, with fluctuating oil prices, low outputs due to poor soil health and insufficient animal farming; we need to develop cost-effective alternatives and newer commercial 
models. It is therefore essential to integrate livestock management and cropping together for sustainable and profitable farming, especially for poor farmers in rain-fed regions [21, 22].

One such socio-commercial model is suggested for massproduction of OM described above [6-8] in a cooperative manner among farmers taking into account readily available raw materials (Table 1). The OM that requires fermentation periods of 14-30 days by manually mixing of the contents can be converted by installing electrically driven fermenter. This reduces manual labour and preparation time to 4-7 days, resulting in increased production of up to 4 and 2.5-5 folds in time and volume, respectively.

In order to highlight, the profitability of such a model system, we first calculated the costs associated with requirements (Table 1) and the revenue generation scheme (Table 2) based on current pricing. We assumed a small cattle farm of 30 animals that produces $10 \mathrm{Kg}$ of dung and $2 \mathrm{~L}$ of urine per day by an animal. In such a small setup it is possible to generate up to 270,000INR ( 4,000 USD) per month. Assuming high spending of 2,000USD for maintenance, one is left with remaining 2,000USD. In India, cattle farms are highly revered due to religious sentiments amongst majority of Indians. Such a socio-commercial model (Figure 1) will lead to revenue generation and permit rural development programmes that include farmers meet, education and women empowerment.

On similar lines, one such project is Venu-Madhuri (VM) in Kolhapur district, India, where 5 different villages pool their resources. In this socio-commercial model, farming and women empowerment is encouraged via cattle farming. Cattle dung- and urine is procured and managed to produce a variety of commercial products such as soaps, incense sticks, ayurvedic medicine etc., along with energy generation and organic manure preparation. Unlike the idea mentioned above for mass-production and revenue generation, VM focuses on "Production by masses rather than mass-production".

\section{Perspective- Good Practise Leads To Good Results}

We have emphasized on the importance of cattle and organic farming as a profitable alternative to curtail use of chemical fertilizers. But our environment is already contaminated with various hazardous chemicals, out of which usage of pesticide, Dichlorodiphenyltrichloroethane (DDT) and their effects has been well documented [23]. In one of our studies, we noticed contamination of $\mathrm{OM}$ with chemical pesticides, most likely via cattle fodder. Farms that have been rigorously using organic farming practises since the last 14 years also had low level of chemical pesticides [6], this highlights the potential problems of obtaining residue free farming practise altogether. Regardless, in order to have a clean green initiative, one will have to start from base line, i.e. organic cultivation and feeding of fodder crops in chemical free environment, and thus obtaining organic-chemical free cow dung and urine (Figure 2). Such practises, where livestock management and agriculture can result in improving economic situation of poor farmers [21,22], should be encouraged. Moreover, when farming communities come together in the form of cooperative societies to maintain livestock and produce OM in bulk; it can result in rural development and dramatically curtail use of synthetic fertilizers.

Table 1: Requirements for preparation and costing (in parentheses) of $500 \mathrm{~L}$ organic manures. INR is the abbreviation for Indian Rupees.

\begin{tabular}{|c|c|c|}
\hline & Panchagavya (Pc) & Jeevamrut (Ja) \\
\hline Cow Dung & $125 \mathrm{Kg}$ (750 INR) & $75 \mathrm{Kg}$ (450 INR) \\
\hline Cow Urine & 125 L (1875 INR) & 75 L (1,125 INR) \\
\hline Gram flour & -- & $12.5 \mathrm{Kg}(1,500 \mathrm{INR})$ \\
\hline Jaggery & -- & $12.5 \mathrm{Kg}$ (750 INR) \\
\hline Cow milk & $60 \mathrm{~L}$ (2400 INR) & -- \\
\hline Cow curd & $60 \mathrm{Kg}$ (6000 INR) & -- \\
\hline Cow cream & $1 \mathrm{Kg}$ (340 INR) & -- \\
\hline Water & $129 \mathrm{~L}$ & $325 \mathrm{~L}$ \\
\hline $\begin{array}{l}\text { Production } \\
\text { cost }\end{array}$ & $\begin{array}{c}=11,365 \mathrm{INR} / 500 \mathrm{~L}(19.45 \\
\text { INR/ L) }\end{array}$ & $\begin{array}{c}=3,450 \mathrm{INR} / 500 \mathrm{~L}(7.65 \\
\text { INR/L) }\end{array}$ \\
\hline
\end{tabular}

Table 2: Revenue generation per month from raw materials available in Cattle farm with 30 cows

\begin{tabular}{|l|l|}
\hline $\begin{array}{l}\text { Quantity of Organic Manure in a } \\
\text { single run }\end{array}$ & $500 \mathrm{~L}$ \\
\hline $\begin{array}{l}\text { Quantity of } P c \text { production in } 1 \\
\text { month }\end{array}$ & $=1,500 \mathrm{~L}$ \\
\hline $\begin{array}{l}\text { Quantity of Ja production in } 1 \\
\text { month }\end{array}$ & $=2,000 \mathrm{~L}$ \\
\hline Selling price of 1 L (Pc/ Ja) & $180 / 120$ INR \\
\hline Grant Total(Pc/ Ja) & $\mathbf{4 6 6 , 0 8 0 ~ I N R / ~ 3 1 3 , 4 0 0 ~ I N R ~}$ \\
\hline
\end{tabular}

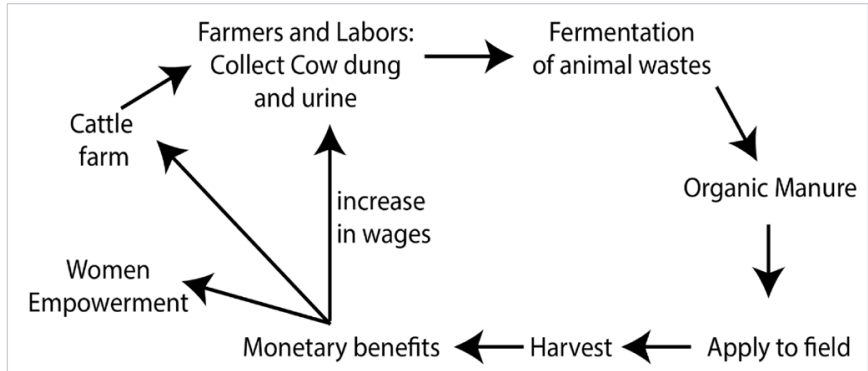

Figure 1: Socio-commercial model depicting the various channels for organic manure production via animal wastes and its scope in rural development.

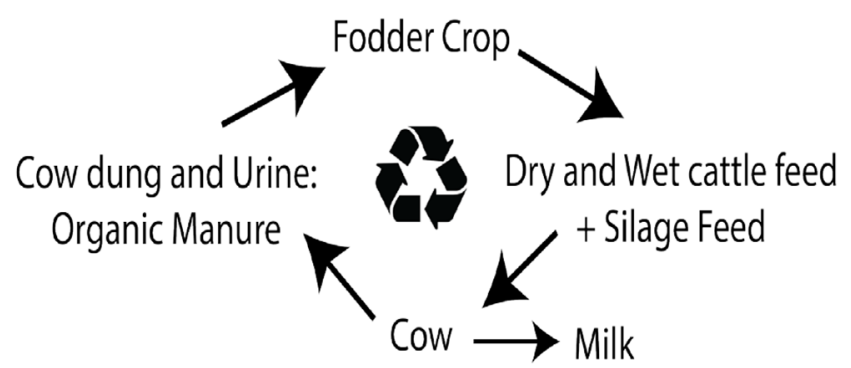

Figure 2: Organic green circle highlighting the process of farming in a closed circuit, thereby eliminating/reducing the scope of contamination by chemical fertilizers and pesticides. 


\section{Acknowledgement}

I would like to thank Vijay Chemicals and Neeti Developers for support and suggestions; Rahul Deshpande from VenuMadhuri; and Dr. Nivedita Cukkemane for critically reading the manuscript.

\section{References}

1. Pingali PL. Green revolution: impacts, limits, and the path ahead. Proc Natl Acad Sci U S A. 2012;109(31): 12302-12308. doi: 10.1073/ pnas.0912953109.

2. Bellur VV, Singh SP, Radharao C, Rajeswararao C. The white revolution - How Amul brought milk to India. Long Range Planning. 1990;23(6): 71-79. doi:10.1016/0024-6301(90)90104-C.

3. Gautam, Dalal RS, Pathak V. Indian dairy sector: Time to revisit operation flood. Livestock Science. 2010;127(2-3):164-175. doi. org/10.1016/j.livsci.2009.09.010.

4. Wang, ZH, Li S X, Malhi S. Effects of fertilization and other agronomic measures on nutritional quality of crops. Journal of the Science of Food and Agriculture. 2008;88:7-23.

5. Nene YL. Potential of Some Methods Described in Vrikshayurvedas in Crop Yield Increase and Disease Management. Asian Agri-History. 2012;16(1):45-54.

6. Ukale DU, Rohit VB, Santosh KU, Nivedita C, Abhishek AC. Metabolic analysis of liquid formulations of organic manures and its influence on growth and yield of Solanum lycopersicum L. (tomato) crop in field. Biocatalysis and Agricultural Biotechnology. 2016;8:50-54.

7. Ali MN, Ghatak S, Ragul T.Biochemical analysis of Panchagavya and Sanjibani and their effect in crop yield and soil health. Journal of Crop and Weed. 2011;7:84-86.

8. Gore N, Sreenivasan MN. Influence of liquid organic manures on growth, nutrient content and yield of tomato (Lycopersicon esculentum Mill.) in the sterilized soil. Karnataka Journal of Agriculture Sciences, 2011;24:153-157.

9. Helga W, Lernoud J. The world of organic agriculture - stastics and emerging trends 2016, ed. Research Institute of organic agriculture (FiBL), IFOAM Bonn. 2016.

10.World-bank [cited 2016] http://data.worldbank.org/indicator/ AG.LND.AGRI.ZS. 2016

11.ICAR, Handbook of Indian Agriculture. 6 ed. 2006;New Delhi: Indian Council of Agricultural Research.
12. National Dairy Development Board, [cited 2012] http://www.nddb. org/information/stats/pop.

13. Press Bureau India, Government of India. Ministry of Agriculture [cited 2014]http://pib.nic.in/newsite/PrintRelease.aspx?relid=109280 .

14. Roy S, Kashem AM. Effects of Organic Manures in Changes of Some Soil Properties at Different Incubation Periods. Open Journal of Soil Science. 2014;4(3):81-86. doi:10.4236/ojss.2014.43011.

15. King LA, Nogareda F, Weill FX, Mariani-Kurkdjian P, Loukiadis E, Gault G, et al. Outbreak of Shiga toxin-producing Escherichia coli 0104:H4 associated with organic fenugreek sprouts, France, June 2011. Clin Infect Dis. 2012;54(11):1588-94. doi: 10.1093/cid/cis255.

16. Burger R. EHEC 0104:H4 in Germany 2011: Large outbreak of bloody diarrhea and haemolytic uraemic syndrome by shiga-toxin producing E. coli via contaminated food. 2012: Institute of Medicine (US). Improving Food Safety through a One Health Approach: Workshop Summary. Washington (DC): National Academies Press (US).

17. Buren AV. A Chinese Biogas Manual, ed. A.v. Buren. Practical Action Publishing. 1979.

18. Raghav S, Sen C. Socio-economic status of farmers and their perception about technology: a case study. EPRA International Journal of Economics and Business Review. 2014;2(3):7-13.

19. Singh TP, Kumbhar V, Kumari S. Study of socioeconomic status of farmers in drought prone regions of Maharashtra, India- a case study. International Journal of Current Research. 2016;8(6):33304-33306.

20. Ananthnag K, Ali MMK, Kumar VHM. A study on socio-economic status of farmers practicing on organic farming in eastern dry zone of Karnataka. Online Journal of Bioscience and Informatics. 2014;1(2):75-84.

21. McDermott JJ, Staal SJ, Freeman HA, Herrero M, Van de Steeg JA. Sustaining intensification of smallholder livestock systems in the tropics. Livestock Science. 2010;130(1-3):95-109.

22. Tarawali S, Herrero M, Katrien D, Elaine G, Michael B. Pathways for sustainable development of mixed crop livestock systems: Taking a livestock and pro-poor approach. Livestock Science. 2011;139(12):11-21.

23. Henk van den Berg. Global Status of DDT and Its Alternatives for Use in Vector Control to Prevent Disease. Environ Health Perspect. 2009;117(11):1656-1663. doi: 10.1289/ehp.0900785. 